\title{
Impact Studies of Distributed Generation on Power Quality and Protection setup of an Existing Distribution Network
}

\author{
B. Hussain*, S.M. Sharkh **, and S. Hussain* \\ */** School of Engineering Sciences, University of Southampton, SO17 1BX, UK \\ *bh1k06@soton.ac.uk**Suleiman@soton.ac.uk
}

\begin{abstract}
The increasing amount of distributed generation (DG) in distribution networks (DNs) is giving rise to power quality and protection coordination problems. Issues like voltage regulation, flicker, harmonics and loss of coordination between circuit breaker and fuse need to be addressed for integration of DG into DN. This paper discusses these issues with a special emphasis on protection coordination problems. A typical DN with DG is modeled and simulation results for impact of DG on protection system coordination are presented and discussed here. Some solutions are proposed to cope with these problems.
\end{abstract}

Index Terms--Distributed generation (DG), microgrid, power quality, protection

\section{INTRODUCTION}

The impact of the distributed generation (DG) on power quality of a distribution network (DN) depends on different factors like the type of DG, its interface with the utility system, the size of the DG unit, its intended mode of operation and expected output fluctuation, the total capacity of the DG relative to the system, size of generation relative to the load at the interconnection point, and feeder voltage regulation practice [1].

Generally, DG installed to provide back up generation and on-site power supply improves the power quality of the system. But this is not always the case. Issues do arise when distributed generators of different types and technologies are connected to DN. The main issues include voltage regulation, voltage flicker, voltage dips, sustained interruptions, harmonics [1-5] and interference with existing utility protection setup [6-12].

This paper presents an overview of the power quality and protection issues in case of DNs with DG. Section II outlines key power quality problems briefly. In section III, important protection issues and conditions in which they can arise are presented and discussed with the help of a case study of a typical DN with DG as shown in Fig.1. ASPEN OneLiner software is used to simulate different fault scenarios to demonstrate and investigate these issues. Section IV discusses the results and proposes some solutions. Finally, section V concludes the findings of the paper.

\section{POWER QUALITY ISSUES}

\section{A. Voltage Regulation}

The voltage regulation problem may arise as a result of introduction of DG into DN for any of the following reasons: intermittent nature of the wind turbine, fuel cells and combined heat and power plants (CHP); interference of the synchronous generators (capable of supplying active and reactive power) with the utility voltage regulating equipment, i.e., with static voltage regulators (SVR) and with load tap changers (LTC); use of induction generators and inverters (for grid connection) that are not suited for voltage regulation as they lack the ability to produce reactive power; use of a small DG unit (which lacks the ability to regulate the voltage); breakdown of a large DG unit (responsible for voltage regulation) in case of a fault on the feeder; lack of coordination between multiple DG units; frequent connection and disconnection of a large number of small DG units - working at a constant power factor- from the network; reverse power flow that occurs when DG output is in excess of downstream feeder load

\section{B. Voltage Flicker}

Voltage flicker is caused by fluctuation of energy which results from intermittent generation from wind turbines and photovoltaic sources, or connection and disconnection of induction generators from the network.

\section{Voltage Dips}

Voltage dips can occur during start up of induction generators (as reactive power is consumed during magnetization), switching away of generator from synchronous speed or due to short circuits.

\section{Sustained Interruptions}

Not all the DG technologies are able to provide backup generation in case of interruptions or breakdown of the main system. DG based on an induction generator, or with an uncontrollable inverter, or lacking proper storage might be unable to operate in island (standalone) mode.

\section{E. Harmonics}

Some forms of DG, i.e., photovoltaic (PV) and fuel cells, are connected to the power network through power electronic converters. The modern converters based on 
insulated gate bipolar transistors (IGBTs) use pulse width modulation (PWM) technique and thus produce fewer harmonics than the old generation of thyristor based line commutated inverters. DG based on induction and synchronous generators change the response of the network to the other harmonic sources by changing harmonic impedance of the network. Moreover, capacitors used for excitation of induction generators can cause resonances in the network.

\section{F. Voltage Unbalance}

Voltage unbalance can occur as a result of integration of a single phase DG, i.e., DG based on PV units, in DN. This unbalance becomes noticeable as more and more single phase DG units are introduced into DN.

\section{PROTECTION ISSUES}

The introduction of DG into DN brings about a change in fault current level (FCL) of the network. This change in FCL can, in turn, alter device discrimination, reduce reach of overcurrent and distance relays, cause sympathetic tripping, force unintentional islanding, and mal-operation of autoreclosures [6-12]. Depending upon the location of the fault with respect to the DG and the existing protection equipment, problems like bidirectionality and change in voltage profile can also arise. To ensure selectivity, proper coordination between relays, reclosures, fuses and other protective equipment is a must. However, this coordination is severely affected when DG is connected to a DN.

Fig. 1 shows a single line diagram of the system that is simulated to investigate the impact of DG on DN protection. A typical $25 \mathrm{kV}$ distribution network (DN) is configured down stream of a $69 / 25 \mathrm{kV}$ substation named as main substation (MS). The utility grid upstream of the substation is represented by a Thevenin equivalent of voltage source and series impedance with short circuit level of $637 \mathrm{MVA}$ and X/R ratio of 8 at $69 \mathrm{kV}$ bus. MS is equipped with a $69 / 25 \mathrm{kV}, 15 \mathrm{MVA}$ load tap-changing transformer, with delta-wye grounded configuration. The transformer has a series equivalent impedance of $7.8 \%$ at 15 MVA base and connects the DN to the $69 \mathrm{kV}$ subtransmission system.

The DN is modeled by two load feeders, named as LF1 and LF2 in Fig. 1, emanating from the $25 \mathrm{kV}$ bus. The system load-10 MW on each feeder- is modeled as constant impedance that has no contribution to the fault. Two equivalent synchronous generators rated at $18 \mathrm{MVA}$ are connected to the $25 \mathrm{kV}$ bus through two $0.66 / 25 \mathrm{kV}$, 18 MVA step up transformers- with delta-wye grounded configuration- and through two $25 \mathrm{kV}$ collector feeders named as CF1 and CF2 in Fig. 1.

The positive sequence impedance for $25 \mathrm{kV}$ feeders is $0.2138+\mathrm{j} 0.2880 \Omega / \mathrm{km}$ and for $69 \mathrm{kV}$ feeder it is $0.2767+\mathrm{j} 0.5673 \Omega / \mathrm{km}$. The zero sequence impedance for $69 \mathrm{kV}$ sub-transmission line (Sub-TL) is $0.5509+\mathrm{j} 1.4514$.

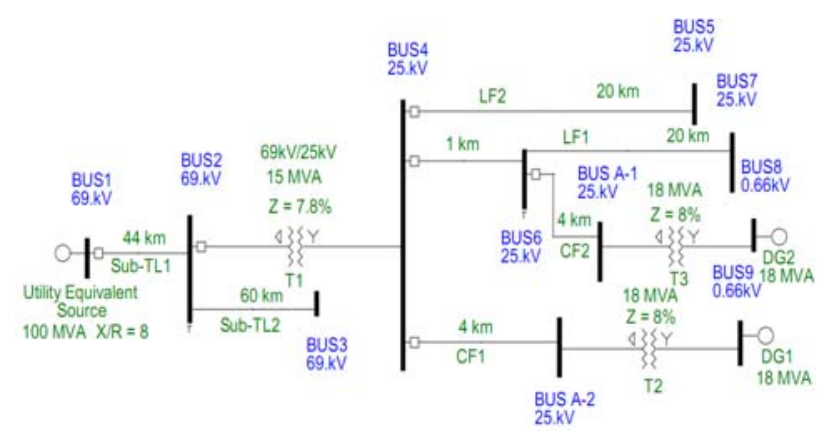

Fig. 1. Single line diagram of a typical distribution network (DN) with distributed generation (DG) where Sub-TL stands for sub-transmission line, CF and LF represent collector feeder and load feeder respectively.

A distance relay (SEL 321) is installed at bus 1 end of the Sub-TL1 to protect against faults at Sub-TL1 and SubTL2 and to provide back up protection for some part of DN. An OC fuse rated at 200 ampere (A) is installed on high voltage side of transformer T1 to provide protection against transformer internal faults and backup for feeder faults. The load feeders are equipped with time graded overcurrent (OC) and earth fault (EF) relays (i.e. 51/51N) and instantaneous $\mathrm{OC}$ and EF relays (i.e. $50 / 50 \mathrm{~N}$ ) for protection against phase and ground faults. The collector feeders are also protected by OC relays. OC and EF relays of load feeders LF1 and LF2 are set at $280 \mathrm{~A}$ and 140 A respectively. OC relays at the both the collector feeders are set at $400 \mathrm{~A}$.

ASPEN OneLiner is used to simulate different faults for determining short circuit levels and to investigate their impact on protection coordination including reach of distance relays. Fig. 2 shows the time-current characteristic curve of the fuse installed at high voltage side of MS transformer and OC relays installed at load feeders. The operating times that are shown on the curve are of fuse and OC relays of load feeders in case of a three phase to ground (3LG) fault at $90 \%$ of the LF1 length.

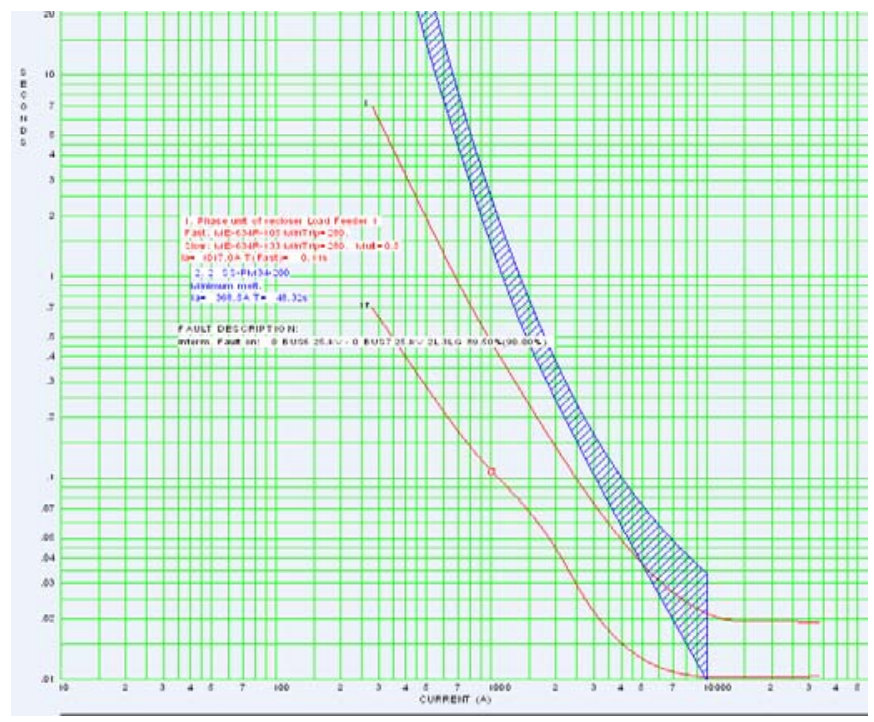

Fig. 2. Operating times of OC relay installed at LF1 and fuse located at high voltage side of substation transformer for $3 \mathrm{LG}$ fault at $90 \%$ of LF 1 length without DG where $1 \mathrm{f}$ is the fast characteristic and 1 is slow characteristic OC relay curve. 


\section{A. Fault Level Modification}

A 3LG fault was applied to find out fault current at different points with and without DG connection as shown in Table I. It is clear from the table that after introduction of DG, fault current has increased by $28.5 \%$ at bus 2 , by $51 \%$ at bus 4 and by $22.8 \%$ in case of a fault at the end of LF1.

TABLE I. FAULT CURRENTS AT DIFFERENT NETWORK BUSES WITH AND WITHOUT DG

\begin{tabular}{|c|c|c|c|c|c|}
\hline \multicolumn{6}{|c|}{ Fault current (in Amperes) } \\
\hline \multicolumn{3}{|c|}{$\begin{array}{l}\text { Without DG while } 3 \text { phase to } \\
\text { ground fault is at }\end{array}$} & \multicolumn{3}{|c|}{$\begin{array}{l}\text { With DG while } 3 \text { phase to ground } \\
\text { fault is at }\end{array}$} \\
\hline Bus 2 & Bus 4 & $\begin{array}{l}\text { End of } \\
\text { LF1 }\end{array}$ & Bus 2 & Bus 4 & $\begin{array}{l}\text { End of } \\
\text { LF1 }\end{array}$ \\
\hline 1147 & 1874 & 967 & 1605 & 3826 & 1252 \\
\hline
\end{tabular}

\section{B. Blinding of Protection}

Operation of a feeder OC relay may be disturbed in the presence of DG. Although DG increases the fault levels but the fault current seen by the feeder OC relay decreases due to DG contribution in situations when DG is located between the fault point and the feeding station as shown in Fig. 3. This can result in delayed tripping of the feeder relay or in worst scenario no tripping at all. It is clear from the Table II, in case of 3LG fault at $90 \%$ of feeder length, OC relay at LF1 operated in 0.23 seconds(s) when no DG was connected and the same relay operated in $0.29 \mathrm{~s}$ when only DG2 is connected or both DG units are connected.

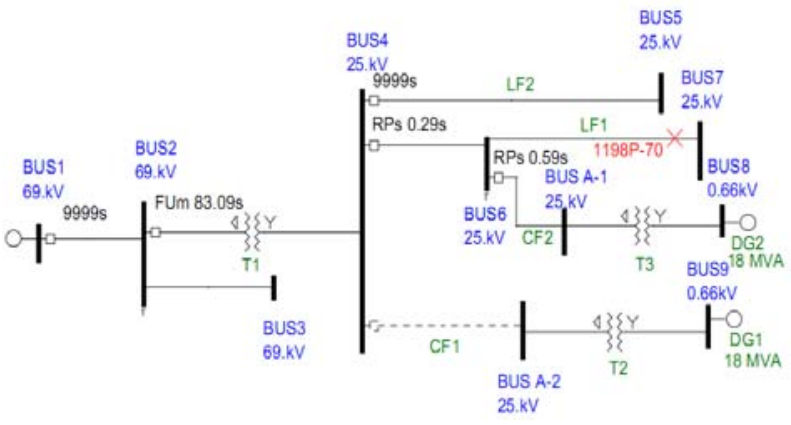

Fig. 3. Blinding of protection or delayed tripping scenario in case of a 3LG fault at $90 \%$ of LF1 length with DG2 connection only.

TABLE II. OPERATING TIMES OF PROTECTION DEVICES IN CASE OF 3LG FAULT AT 90\% OF LF1 LENGTH (N/O stands for no operation and DR stands for distance relay)

\begin{tabular}{|l|l|l|l|l|l|}
\hline $\begin{array}{l}\text { Configuration } \\
\text { of DN }\end{array}$ & \multicolumn{5}{|c|}{ Operating time (second) } \\
\hline \multirow{3}{*}{ W/O DG } & $\begin{array}{l}\text { DR } \\
\text { (Zone 3) }\end{array}$ & Fuse & $\begin{array}{l}\text { OC } \\
\text { relay at } \\
\text { LF1 }\end{array}$ & $\begin{array}{l}\text { OC } \\
\text { relay at } \\
\text { CF 1 }\end{array}$ & $\begin{array}{l}\text { OC } \\
\text { relay at } \\
\text { CF 2 }\end{array}$ \\
\cline { 2 - 6 } & N/O & 48.32 & 0.23 & N/O & N/O \\
\hline With DG 1 & N/O & 79.85 & 0.18 & 0.58 & N/O \\
\hline With DG 2 & N/O & 82.09 & 0.29 & N/O & 0.59 \\
\hline With both DGs & N/O & 64 & 0.29 & 0.89 & 0.9 \\
\hline
\end{tabular}

\section{Sympathetic Tripping}

Some times a DG can contribute to a fault on a feeder fed from the same substation or even to a fault at higher voltage levels resulting in unnecessary isolation of a healthy feeder or a DG unit. For example, an OC relay at
CF1 can unnecessarily operate for a high resistive 3LG fault at LF1 as a result of infeed to the fault from DG1 through the substation bus bar as shown in Fig. 4.

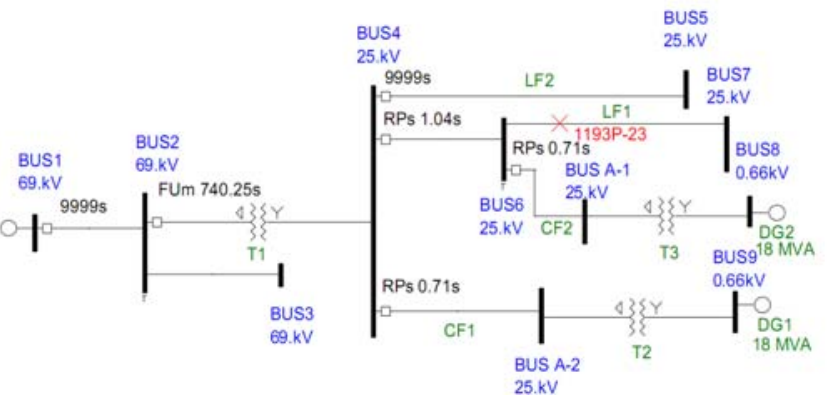

Fig. 4. Sympathetic tripping scenario when relay at CF1 opens for a high resistive $3 \mathrm{LG}$ fault at $30 \%$ of LF 1 length with both DG connected.

\section{Reduction in Reach of Distance Relay}

Distance relays are set to operate in a specific time for any faults occurring within a predefined zone of a transmission line or a distribution feeder. Due to presence of DG, a distance relay may not operate according to its defined zone settings. When a fault occurs downstream of the bus where DG is connected to the utility, impedance measured by an upstream relay will be higher than the real fault impedance (as seen from the relay). This can disturb the relay zone settings and can, thus, result either in delayed operation or in some cases no operation at all. Table III shows the zone settings for the distance relay installed at the Sub-TL 1(shown in Fig. 1).It is clear from the table that range of zone 2 decreases to $67 \%$ when DG is connected from $79 \%$ when no DG was connected. Similarly, reach of zone 3 is reduced to $91 \%$ with DG from its previous value of $100 \%$ when no DG was connected. Zone2 underreach is also shown in Fig. 5.

TABLE III. OPERATING ZONES OF DISTANCE RELAY WITH AND WITHOUT DG

\begin{tabular}{|c|c|c|c|c|c|}
\hline \multirow[t]{3}{*}{ Zones } & \multirow{3}{*}{$\begin{array}{l}\text { Relay } \\
\text { settings } \\
\text { (\% of } \\
\text { line } \\
\text { length) }\end{array}$} & \multicolumn{4}{|c|}{ Distance relay operating range } \\
\hline & & \multicolumn{2}{|c|}{3 phase fault } & \multicolumn{2}{|c|}{1 phase fault } \\
\hline & & $\begin{array}{l}\text { w/o } \\
\text { DG }\end{array}$ & $\begin{array}{l}\text { with } \\
\text { DG }\end{array}$ & w/o DG & with DG \\
\hline Zone 1 & 40 & 40 & 40 & 39 & 39 \\
\hline Zone 2 & 80 & 79 & 67 & 79 & 74 \\
\hline Zone 3 & 115 & 100 & 91 & 100 & 100 \\
\hline
\end{tabular}

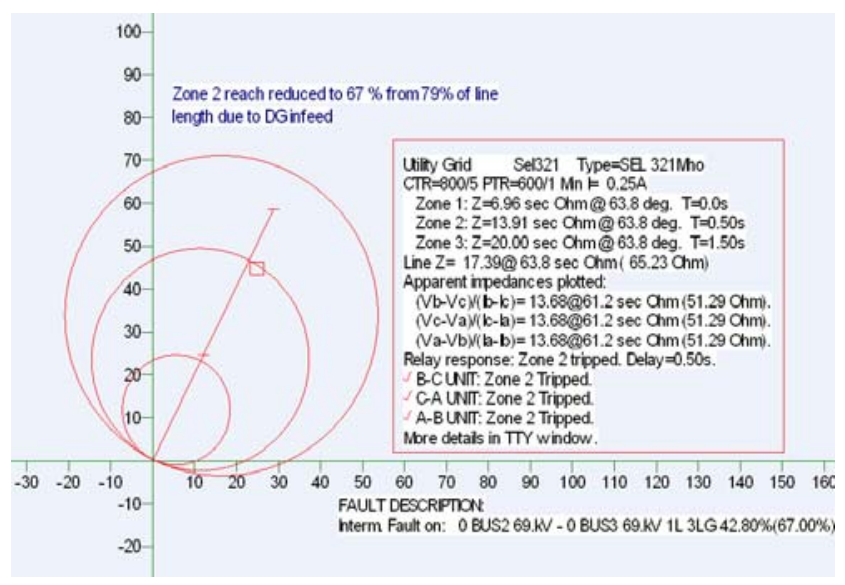

Fig. 5. Distance relay zone settings and effect of DG on Zone 2 reach 


\section{DISCUSSION OF RESULTS}

The simulation results clearly show the impact of DG on operation of different protective relays. Most of the problems that may arise can be solved by use of modern microprocessor based multi-function relays with more features and readjustment of relay settings. For example, replacing simple OC relays with directional relays on collector feeders can solve the problem of sympathetic tripping. In this case, additional relays would be required to provide back up protection to $25 \mathrm{kV}$ bus bar. To solve the problem of delayed tripping, current setting of the relay at LF1 can be lowered. But this needs great care, as if the setting is too low, nuisance tripping can occur in severe overload conditions. Another solution is to have relays with two groups of settings; one group for operation without DG and the other group for operation with DG. For its working, this scheme requires a communication link between the OC relays at LF1 and the relays at collector feeders.

So far as underreaching of distance relay is concerned, readjustment of zone settings or addition of an extra zone can make the relay to operate in the correct zone. However, the distance relay can over reach if the DG units are disconnected. Therefore, these conditions should be checked to ensure that there is no mis-coordination with the adjacent Zone 2 . Installation of one $25 \mathrm{kV}$ circuit breaker and a multifunction protective relay including $50 / 51,50 / 51 \mathrm{~N}, 67,67 \mathrm{~N}$ and other functions can provide fast interruption of fault current infeed for transformer faults, primary protection for the $25 \mathrm{kV}$ bus bars and local backup protection in case of failure of collector feeder relays. The preferred location for this circuit breaker is LV side of MS transformer.

\section{CONCLUSIONS}

The paper investigates power quality and protection issues that can arise in case of DNs with DG with the help of a case study. By making use of a simulation model of a typical DN, different fault scenarios, i.e. with and without DG, have been simulated and behaviour of an existing protection set up has been examined. The results show that DG integration can change fault current level and, consequently, coordination of protection devices. Nuisance tripping of relays can also occur. Distance relays can underreach as a result of fault current infeed from DG. All these issues should be addressed in order to ensure that protection of system remains reliable even after introduction of DG.

\section{REFERENCES}

[1] El-Samahy and E. El-Saadany, "The effect of DG on power quality in a deregulated environment," IEEE Power Engineering Society General Meeting, vol. 3, Jun 2005, pp. 2969- 2976.

[2] N. Jenkins, R. Allan, P. Crossley, D. Kirschen and G. Strbac, 'Embedded Generation' IEE Power and Energy Series 31, London, 2000.

[3] R. C. Dugan, M. F. McGranaghan, S. Santoso and H. W. Beaty, 'Electric power systems quality', 2nd edition, McGraw-Hill Professional Engineering, New York, 2002.

[4] CIGRE, (1999), "Impact of Increasing Contribution of Dispersed Generation on the Power System," Working Group Report 137, February 1999.

[5] P. P. Barker and R. W. de Mello, "Determining the impact of distributed generation on power systems. I. Radial distribution systems," IEEE Power Engineering Society Summer Meeting, Vol. 3, pp. 1645-1656, 2000

[6] Martin Geidl, 'Protection of Power Systems with Distributed Generation: State of the Art', Power Systems Lab. ETH Zurich.

[7] CIRED WG04: Dispersed generation - Preliminary Report, CIRED99, Nizza (Fr), 2-5 Giugno1999.

[8] Distribution System Design for Strategic Use of Distributed Generation. EPRI, Palo Alto, CA: 2005. 1010671.

[9] Z. Chen, W. Kong, 'Protection Coordination Based on Multi-agent for Distribution Power System with Dist. Generation Units'.

[10] T. K. Abdel et al., 'Protection Coordination Planning With Distributed Generation', Qualsys Engco. Inc. CETC Number 2007-49/2007-09-14.

[11] W. E. Feero, et al., "White paper on Protection Issues of The MicroGrid Concept", Consortium for Electric Reliability Tech. Solutions, 2002

[12] Power System Relaying Committee, IEEE Power Engineering Society, 'The Impact of Distributed Resources on Distribution Relaying Protection', August 2004. 